\title{
Architecture for Personalized Service System of Logistics Business Information
}

\author{
Qi Zhang, Faheng Wu, Xiaogen Su and Jianxin Deng* \\ Guangxi Key Lab of Manufacturing System and Advanced Manufacturing Technology, \\ School of Mechanical Engineering, Guangxi University, Nanning, Guangxi, China \\ *Corresponding author
}

\begin{abstract}
Logistics business information plays an important role in data-driven logistics operation and optimization. However, with the increase of the collected logistics business information, the cost and time taken to search interested and right information also increase. To address this problem, this paper introduces personalized information technology to logistics business discovery. The information of logistics business was characterized with big data. The personalized service requirements of logistics business information was formulated, and the requirements model was developed by using UML. Then an architecture for personalized service system of logistics business information (PSSLBI) was presented. It is the foundation to divide system functions and develop high-quality personalized service of logistics business information.
\end{abstract}

Keywords-logistics business information; personalized information service; proactive service; architecture design; requirements model

\section{INTRODUCTION}

In the recent years, with the development of E-commerce and aggravation of business competition among enterprises, logistics as the third source of benefits has attracted much attention and investments around the world. In China, the total volume of logistics increase rapidly [1]. However, compared with developed countries like USA and Germany, the average social logistics cost of China still keep higher level. The lower level of logistics information operations was reported to be one of the important reasons, which causes the relevant logistics parties are blind to their mutual business requirements, accordingly results in low efficiency of scheduling and high empty-loading ratio. Developing logistics information platform is a successful effective solution that to a great extent plays important roles on business types expansion, increase of sale channels and development of new market areas[2].Thus, to address the above problems, a great number of data-driven logistics information platforms based on Internet and Web technology have been developed by governments and enterprises to collect and share logistics business information in China. Meanwhile, researches on logistics information platforms become active, which focused on development technology, architecture[3-7],pricing rules[8] and auction mechanism[9].Nevertheless, with the increase of business information data at such a platform, no matter how accurate the information describes the business, for any companies, the exponentially increasing information causes the problem of information overload, among of which are invalid and uninterested of specific users. The time and cost spent on searching interested information in a traditional way like by keywords are increasing greatly. It has been leading the discovery of logistics business to the prisoner's dilemma[10] and facing several challenges[11]. Furthermore, it makes the information gradually lose the trust from all partners participating in collaboration. One way to overcome this problem is to develop intelligent recommendation system to provide personalized information service[12].Personalized information service demonstrated its effectiveness in different domains, especially in the digital library, social media, ecommerce domains like Amazon[13].However, to our best knowledge, personalized information recommendation system of logistics platform is rarely discussed in literature. Therefore, this paper proposes to develop personalized information service for logistics business, which can collect information of logistics businessmen and build interests model incorporating their requirements, then provide proactive recommendation service of logistics business information, so as to decrease the time and cost spent on business discovery.

The remainder of this paper is organized as follows. Section 2 analyzes the characteristics of Chinese logistics business information. Section 3 formulates the personalized service requirements of logistics business information and sets up the user case model of requirements. Section 4 presents an architecture for personalized information service system of logistics business. And Section 5 summarizes the key points of the paper.

\section{CHARACTERISTICS OF CHINESE LOGISTICS BUSINESS INFORMATION}

Logistics business information(LBS) points the information about logistics business, such as cargoes, vehicles, storage, packaging information. In recent years, with the rapid development of Chinese logistics industry and the application of information technology, a great deal of logistics enterprises have transformed their services from traditional means to electronic ones, LBS is increasing gradually as big data. The LBS now has the following features.

\section{A. Large Volume}

On one hand, due to the development of E-commerce and its advantages of low price and convenience, more and more people like to buy articles through Internet, which makes a great increase of logistics requirements. On the other hand, to promote the management and communication of logistics business, a lot of logistics information or service platforms (or websites) have been developing, like the Chinese Logistics 
Information Platform, FaLa Platform, Soo56.com, China Wutong, JC Trans and First Cargo. These platforms gather a great deal of logistics business information through Internet. And the information volume is now explosively growing with the increase of users. Although to a large extent these websites improve the abilities of the relative users like cargo owners to get their right information and handle the logistics business, the big volume of these types of information is gradually overloading than they need. Thus it is more difficult to get the right information.

\section{B. Various Types}

Logistics business includes a couple of activities like transportation, storage, as well the different requirements of each user, accordingly there are a series of different types of business information related to the activities. From the logistics functional perspective, they are usually classified as transporting information, storage information, loading information, packaging information, distribution information, etc. And each category has some branches, for example, as for the transporting information, it involves the transporting information of ordinary cargoes and special cargoes like dangerous cargoes.

\section{Heterogeneous Expressions}

Due to a lack of universal expression standard of each type of logistics activity, the corresponding information from different logistics platforms or websites has various structures, different names for the same variable like the cargo weight. In addition, for each end user, to expand their business, they tend to publish their same business requirement on a couple of platforms. Accordingly, this leads to the same business has various different descriptions because of the expression differences mentioned above. Naturally, the owner of each logistics business information will get a great amount of matched business information though they are for the same requirement. It consumes more processing time and cost of the information owner.

\section{Personalized ReQUiRements Model Of Logistics BUSINESS INFORMATION}

\section{A. Personalized Information Requirements}

Due to the factors listed above, the information quality of the end users can not be guaranteed. However, most logistics information platforms still only provide pure manual ways or simple combined ways to search for useful logistics business information. The users have to spend more time and cost to process these data to achieve right business information. This naturally postpones the users getting business, or will limit them to take full advantage of the information and carry out logistics business. Thus they require personalized information service to help them get right information at right time at a low cost.

(i)There is still a need of some professional logistics operation knowledge during carrying out business discovery in data-driven platforms, such as geographic knowledge, cost knowledge and logistics operation rules. Whereas most of users lack such logistics knowledge, which leads to they cannot perform some complex operations and cannot judge whether the business is suitable for them in time. For example, though someone obtained a piece of information on special cargoes, he hesitate to decide whether or not his vehicle matches these cargoes due to he don't understand the detailed principles on special cargoes. Moreover a lot of information are generally invalid or unrelated. If they are not filtered through tools automatically, it must waste a lot of manpower and resources.

(ii)Most users of the common platforms are small-andmedium scaled logistics companies. They are weak in information technology and lacking of money. Their employees generally cannot handle complex business searches due to they are not good at computer operations, at the same time hiring computer technicians means high cost. In addition, it is seldom possible that their employees have a long work time to sit in front of computers only for discovering business and tracing real-time changes of business information. This means more for individual logistics drivers, they have to focus on driving not on real-time business information.

(iii)Some repetitive operations are required to be simplified and need more humanization and intelligence, like posting demand information. For example, some manufacturing enterprises' products and the place where products to be transported are fixed. But in conventional way, after they completed a business and ready to start another, they have to re-enter the similar demand information in order to find logistics provision information again. Similarly, a warehouse as a fixed assert whose structure will not change more, the only change maybe is the status data. If a logistics information platform does not make good use of user's transaction information and predict their next requirements. The corresponding operator has to release business information on this warehouse again and again for a continual transaction.

And in terms of operations of computer systems, the requirements mentioned above can be summed up as the following four operations.

Operation 1: to release business information in personalized way. This means personalized devices and simplification. Personalized devices mainly point users can release information through a variety of terminals like smart phones, tablet PCs and other smart devices. Therefore it requires to consider different user's environment and personalized preferences about releasing means and make compatible with these device options. Simplification refers to users could release business information rapidly on their own business area, rather than doing more selections and complex inputs, such as data re-entry of the own vehicle, because of selections are time consuming and lower values according to IE(Industrial Engineering). This requires us to classify user's actions that which are one-time actions, general repetitive actions, necessary repetitive actions and useless actions.

Operation 2: to obtain personalized business information. It points users of logistics platforms could automatically get the interested information they need using a couple of interfaces like personal mail and smart phone message, without additional complex search after releasing their requirements on a platform. For instance, an individual trucker only needs cargo transport information matching with his 
vehicle. This requires the systems can automatically match a various of types of business information and recommend matched results to their corresponding users.

Operation 3: to obtain information offline. As mentioned above, many logistics enterprises are small-and-medium scaled in China. There are much uncertainty of time and approaches for them to get information. Obtaining information offline promotes the possibility of get total information, meanwhile decreases online time consumption which will be spent on business operation.

Operation 4: to read information through personalized means. It is similar to Operation 1 . The users can read the business information by the way as they want. It also needs the platform systems support various terminals and interfaces to review business information without complex operations.

\section{B. Requirements Modeling}

The main purpose of requirements modeling is to obtain and separate the functions of the personalized service of logistics business information, namely what work the implementation system will provide. In order to formulate the model, user case modeling by UML has been utilized.

Based on the above analysis, three major types of users are interested in the logistics business information of all logistics platforms, which can be generalized to carriers(vehicle owners), warehouse owners and shippers. Combined with the four personalized operations, about fourteen required customization services are generated by these users, for example, to release supply information of transport vehicles, to browse demand information of cargoes that system recommended, to release information of warehouses, to browse demand information of warehousing, and so on. Please see Table 1 for the details of all user cases of the personalized service system of logistics business information. And according to the relationships between users and requirements, the user case model of PSSLBI is shown in Figure 1.

\section{Architecture Of The Personalized Service SYSTEM OF LOGISTICS BUSINESS INFORMATION}

To meet the personalized requirements formulated above, the personalized service system of logistics business information is proposed in this paper, which can be a single system or be integrated into any logistics platforms. The logic principle of PSSLBI is suggested as follows:(i) PSSLBI collects the information about logistics users' behaviors, including the registered information, logistics business browsed and released of users, etc. (ii) Analyze the users' potential or possible logistics business requirements basing on these information collected, and show them by a computer readable interest model.(iii)Match the interest model of the users' logistics business requirements and the resource of logistics business information. (iv) Actively send these matched information results to users by their required ways. Moreover, PSSLBI are proposed to apply a four-layer structure as shown in Figure 2 so as to implement the principles and required functions with high quality.

TABLE I. USER CASES OF PERSONALIZED SERVICE SYSTEM OF LOGISTICS BUSINESS INFORMATION

\begin{tabular}{|c|c|c|}
\hline No. & Case Name & Description \\
\hline $\mathrm{U} 1$ & $\begin{array}{l}\text { To browse demand information of } \\
\text { transported cargoes }\end{array}$ & Carriers browse recommended demand information lists of transported cargoes. \\
\hline $\mathrm{U} 2$ & $\begin{array}{l}\text { To release information of transport } \\
\text { vehicles }\end{array}$ & $\begin{array}{l}\text { Carriers publish information of cargo transportation such as the type of car, price range, } \\
\text { departure time, departure, destination, etc. }\end{array}$ \\
\hline U3 & $\begin{array}{l}\text { To customize demand information of } \\
\text { cargoes transported }\end{array}$ & $\begin{array}{l}\text { Carriers choose to pay attention to a certain kind of demand information of cargo transportation } \\
\text { in a certain area. }\end{array}$ \\
\hline $\mathrm{U} 4$ & $\begin{array}{l}\text { To browse warehousing demand } \\
\text { information }\end{array}$ & $\begin{array}{l}\text { Warehouse owners browse recommended demand information lists of warehouse in the } \\
\text { information platforms. }\end{array}$ \\
\hline U5 & To release warehousing information & $\begin{array}{l}\text { Warehouse owners release idle warehousing information such as warehouse location, price } \\
\text { range, warehouse size and warehouse type(if frozen),etc }\end{array}$ \\
\hline U6 & $\begin{array}{l}\text { To customize demand information of } \\
\text { cargoes warehoused }\end{array}$ & $\begin{array}{l}\text { Warehouse owners choose to pay attention to a certain kind of demand information of cargo } \\
\text { warehousing in a certain area }\end{array}$ \\
\hline U7 & $\begin{array}{l}\text { To release demand information of } \\
\text { cargoes transported }\end{array}$ & $\begin{array}{c}\text { Vehicle owners publish information of cargo transportation such as cargo shipment, departure, } \\
\text { destination, etc }\end{array}$ \\
\hline U8 & $\begin{array}{l}\text { To browse information of transport } \\
\text { vehicles }\end{array}$ & $\begin{array}{c}\text { Shippers browse recommended information lists of transporting car in the information } \\
\text { platforms. }\end{array}$ \\
\hline U9 & To customize information of vehicles & $\begin{array}{l}\text { Shippers choose to pay attention to a certain kind of information of transporting car in a certain } \\
\text { area }\end{array}$ \\
\hline $\mathrm{U} 10$ & $\begin{array}{l}\text { To customize information of } \\
\text { warehousing }\end{array}$ & $\begin{array}{l}\text { Shippers choose to pay attention to a certain kind of information of warehousing in a certain } \\
\text { area }\end{array}$ \\
\hline U11 & To browse warehousing information & Shippers browse recommended information lists of warehouse in the information platforms. \\
\hline $\mathrm{U} 12$ & $\begin{array}{l}\text { To release demand information of } \\
\text { cargo warehousing }\end{array}$ & Shippers release demand information of cargo warehousing \\
\hline $\mathrm{U} 13$ & To collect information & $\begin{array}{l}\text { Users are interested in particular business information, for some reason they can't trade } \\
\text { immediately, they can add the business to favorites }\end{array}$ \\
\hline U14 & To require trading & $\begin{array}{l}\text { Users can send a transaction request to the other party when they find the information they } \\
\text { needed }\end{array}$ \\
\hline
\end{tabular}




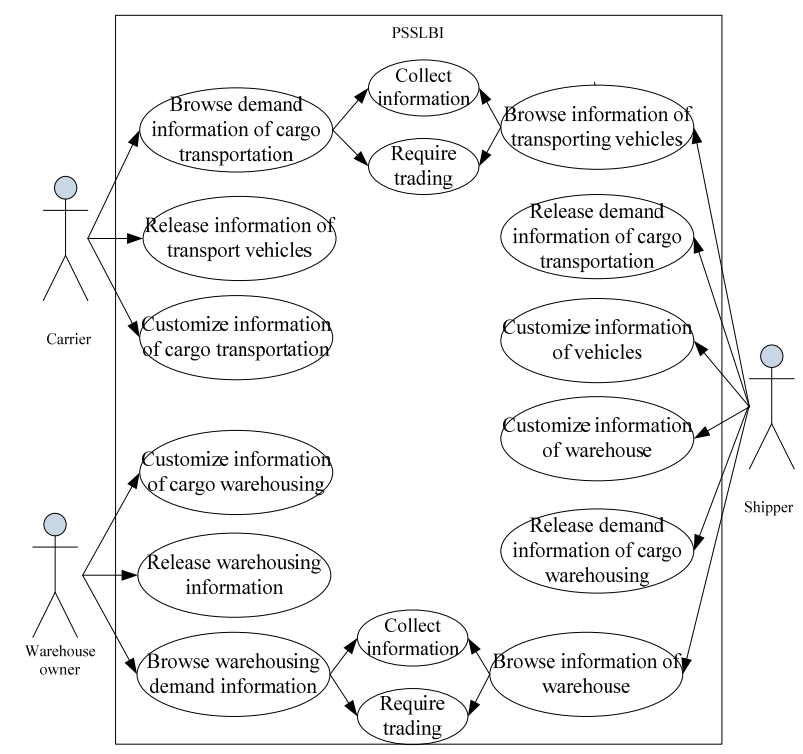

FIGURE I. USE CASES OF PSSLBI

The presentation layer is the interface between PSSLBI and users, mainly achieves all personalized services of logistics business information by providing various interfaces of business activities. Users registers their accounts and basic information, input their logistics business requirements and some preferences like business area and preferred devices. PSSLBI feeds back with the matched business information sets. This layer generally includes the modules of user registration, releasing and customizing business, browsing recommended logistics business information and selecting collections or transactions, which should adapt to different terminal environment.

The application layer is the foundation of the personalized information service, which interacts with the presentation layer directly and provides personalized service support. Its functions mainly involves four aspects:(i) Firstly, it will save the logistics business information which is released by users and translate the text information from presentation layer into statistics which logistics service platforms needed. (ii)Automatically monitor and record logistics business information browsed by every user and corresponding operating behaviors(collect, trade, etc.). Meanwhile, complete capturing the users' interested information. (iii) Application layer should dig the user interests out according to the collected information, then set up the user interests model and get the users interested demand by calculating interests degree. (iv) According to different logistics users and business matched model, the application layer recommend the logistics business information which is accorded with user requirements to the presentation layer. And this is based on a certain algorithm of matching recommendation, realizing the automation and individuation of the logistics business obtaining.

The resource layer is the data convergence layer and the basis of users interest model and recommendation, which

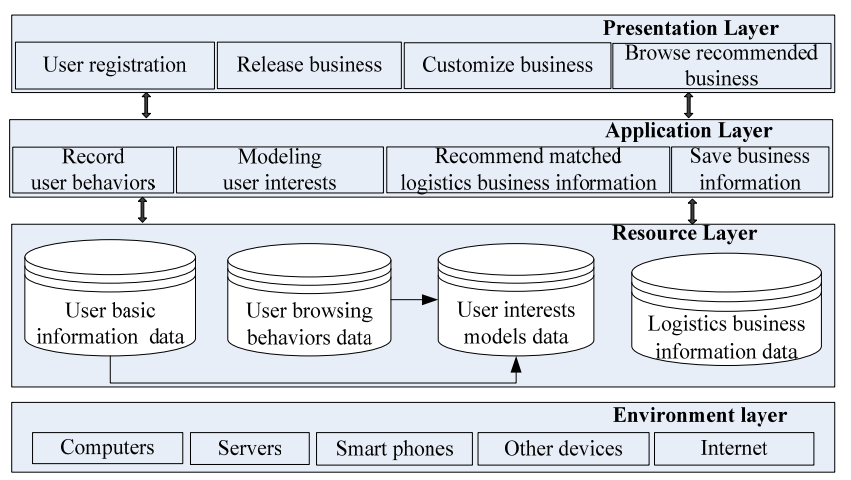

FIGURE II. THE ARCHITECTURE OF PSSLBI

record all user information from the logistics business information platforms, including the logistics business information released by the users, their behavior records and interests models.

The environment layer represents the hardware environment which can realize personalized service of logistics business information, including computers, servers, portable terminals and internet, etc. Since this paper is based on the current logistics public information platforms, there are no big changes to hardware. The hardware facilities is not the research emphasis of PSSLBI.

\section{CONCLUSIONS}

With the development of Chinese logistics industry and lots of logistics information platforms Web-based, the logistics business information is becoming big data, with features of large volume, various types and heterogeneous expressions. It increases the time and cost their relevant users spent on business discovery through them and is impairing their advantages in terms of information sharing. To overcome this problem, this paper proposes to develop personalized information service of logistics business. The personalized requirements and model of logistics business information have been achieved, mainly originating from three reasons. The personalized operations of logistics business information among platforms could be formulated as releasing and reading business information in personalized way and obtaining personalized business information offline. An four-layer architecture for personalized information service of logistics business is set up, encompassing the presentation layer, the application layer, the resource layer and the environment layer. Through this schema, the core principles of personalized information service and the forementioned requirements can be integrated together with good logic relationships.It enable us to divide the functions of PSSLBI well and play a basic role of development.

\section{ACKNOWLEDGMENT}

The authors would like to take this opportunity to thank Natural Science Foundation of China (Grant No.71562002) for supporting this work. Funding by Guangxi Natural Science Foundation of China (Grant No.2014GXNSFBA118281) is gratefully acknowledged. 


\section{REFERENCES}

[1] He Liming,"Timely rain in new normal-undertanding of midle-long planing of logistics industry(2014-2020)”, Chinese Logistics\& Purchasing, pp.26-27,2014.(In Chinese)

[2] Mats, Brege S., "Structural changes in the supply chain", The international journal of logistics management, vol.8, pp. 35-44, 1997.

[3] Yang cui,"Study on construction of logistics public information platform”, Logistics Technology, vol.31, pp. 135-137, 2012.(In Chinese)

[4] Geng Qingxia,Dong Lei,’Research on framework of virtual logistics enterprise information platform based on MAS under grid circumstances”, Logistcs Sci-Tech, pp.99-103,2011.(In Chinese)

[5] Lu Zhibin,Li Liangbao,”Analysis and construction for city logistics information platform”,Logistics Sci-Tech,pp.8-10,19, 2013 .(In Chinese)

[6] Jiang Dali,"Application of CORBA technology to the construction of information platform for virtual logistics”,Journal of Logistics Engineering University,vol.27, pp. 69-74, 2011.(In Chinese)

[7] Zuo Hong,'Investigation report of Hunan logistics public information platform”,Logistics Sci-Tech, pp.24-27,2013.(In Chinese)

[8] Wang Yuzheng,Study on information service pricing of regional logistics information platform, Beijing: Beijing Jiaotong University, 2012.(In Chinese)

[9] Ge Luqing,The research on mechanism of multidimensional aution on logistics public information platform, Shanghai: Tongji University, 2008. (In Chinese)

[10] Pan Xuwei, Li Zebiao, Zhu Xiyong and Shao Chengxi,”Self-adaptive personalized information service: a context-aware and ontology based methodology”,Journal of Library Science in China, vol.35, pp.41-48, 2009.(In Chinese)

[11] Jenkin Tracy A., Chan Yolande E., Skillicorn David B. and Skillicorn Keith W.,'Individual Exploration, Sense making, and innovation: a design for the discovery of novel information”, Decision Sciences, vol.44, pp. 1021-1057-, 2013.

[12] Mashal, Ibrahim, AlsaryrahOsama and Chung Tein-Yaw,’Performance evaluation of recommendation algorithms on Internet of Things services”,Physica A, vol.451, pp.646-656, 2016.

[13] Feng Haoyuan, Tian Jin, Wang Harry Jiannan and Li Minqiang,"Personalized recommendations based on time-weighted overlapping community detection”, Information \& Management,vol.52, pp.789-800, 2015. 